\title{
Environmental and genetic factors affecting faecal worm egg counts in Merinos divergently selected for reproduction
}

\author{
Z. Mpetile ${ }^{1}$, S.W.P. Cloete ${ }^{1,2}$, A.C.M. Kruger ${ }^{2}$ \& K. Dzama ${ }^{1}$ \\ ${ }^{1}$ Department of Animal Sciences, Stellenbosch University, Matieland 7602, South Africa \\ ${ }^{2}$ Directorate Animal Sciences: Elsenburg, Western Cape Department of Agriculture, Elsenburg 7607, South Africa
}

(Received 23 March 2015; Accepted 4 October 2015; First published online 9 December 2015)

Copyright resides with the authors in terms of the Creative Commons Attribution 2.5 South African Licence.
See: http://creativecommons.org/licenses/by/2.5/za
Condition of use: The user may copy, distribute, transmit and adapt the work, but must recognise the authors and the South African
Journal of Animal Science

\begin{abstract}
Infestation with gastrointestinal nematodes is probably among the most pervasive problems in smallstock production worldwide. Faecal worm egg count (FWEC) has been reported as an indirect measure of parasite resistance in livestock production. Environmental and genetic factors of FWEC were assessed, using data from Merino sheep that were selected divergently for reproductive performance at Elsenburg Research Farm. Data consisted of animals born in 1995 - 1996, 1999, and 2001 - 2013. Two datasets were considered: 1869 FWEC records of animals born in the years provided above, and 851 records of the divergently selected lines and the reciprocal cross between them, born in 2003 - 2008. Rectal faecal sample grabs were obtained from individual animals after drenching had been withheld for approximately 6 to 10 weeks, generally in April. Nematode eggs in these samples were counted using the McMaster technique, with a sensitivity of $100 \mathrm{eggs} / \mathrm{g}$ wet faeces. The fixed effect of birth year $\mathrm{x}$ sex interaction was significant, with rams showing higher mean values for FWEC than ewes in most years, but these results were not consistent. FWEC showed significant but low heritability, estimates ranging from 0.06 for untransformed data to 0.10 for log-transformed data, suggesting that selection for low FWEC could be slow. There was no hybrid vigour and compelling evidence of genetic change in log-transformed FWEC in either line, suggesting a negligible genetic correlation between FWEC and reproduction. In this experiment, the researchers studied animals that had been exposed to parasite challenge in autumn. Therefore, the results of this study cannot be applied directly to a situation in which faecal samples were collected in other seasons. Future work is needed to determine the effect of season on the heritability of parasite resistance in South African conditions.
\end{abstract}

Keywords: Breeding values, gastrointestinal nematodes, genetic parameters, heritability, resistance

\# Corresponding author: schalkc@elsenburg.com

\section{Introduction}

Infestation with gastrointestinal nematodes is probably among the most pervasive problems in smallstock production worldwide. It results in substantial losses through reduced growth rates, poor production performance and reduced reproductive efficiency (Chiezey et al., 2008; Kelly et al., 2010; Van Houtert \& Sykes, 2010). There is thus reduced overall production efficiency stemming from high costs of anthelmintic drenches used for prevention and treatment (Pathak \& Tiwari, 2013), and, in severe cases, the death of infested animals (Barger \& Cox, 1984).

For decades, gastrointestinal nematodes have been controlled by using chemical drenches to treat infestation and prevent production losses associated with infestation, hence improving overall production efficiency (Dash, 1986). However, resistance of gastrointestinal nematodes to the chemicals used for treatment has become common (McLeod, 1995; Kenyon et al., 2009; Molento et al., 2011). Thus, relying on drenching with chemicals as the only treatment strategy for controlling gastrointestinal nematode infestations may not be sustainable. Additionally, the use of excessive drugs in meat production could result in chemical residues in meat products if proper withdrawal times are not observed, which could negatively affect human health. This underscores the need to consider alternative strategies of parasite control, such as breeding for parasite resistance as part of the long-term strategy for controlling gastrointestinal nematode infestation in a sustainable manner.

The basic principle of animal breeding and genetics is to improve livestock profitability through selection. Its application in a breeding programme would result in cumulative and permanent gains in desired 
traits. However, for breeding to be implemented, genetic variation of a trait of interest should be present. Literature has reported a variation in parasite resistance, measured indirectly by faecal worm egg count (FWEC), ranging from 0.00 to 0.51 (Greeff et al., 1995; Cloete et al., 2007; Matebesi-Ranthimo et al., 2014). Selecting animals with the lowest FWEC would thus improve parasite resistance in sheep production.

Gray (1991) identified FWEC as a viable means of indirectly measuring parasite resistance. As a result, FWEC has been used widely to measure parasite resistance, following artificial or natural infestation (Mandonnet et al., 2001; Cloete et al., 2007; Matebesi-Ranthimo et al., 2014). Previous studies have reviewed genetic factors that affect FWEC at international level (Khusro et al., 2004; Safari et al., 2005; Morris, 2011; Pickering et al., 2012). However, in South Africa, these genetic factors have been limited to the works of Nieuwoudt et al. (2002), Snyman (2007), Cloete et al. (2007) and Matebesi-Ranthimo et al. (2014), all reporting data of flocks under institutional control. Therefore, the issue of genetic and environmental factors affecting FWEC still needs to be investigated to ensure that these results are robust across environments.

The objective of this study was thus to determine environmental and genetic sources of variation in the FWEC data of the Elsenburg Merino flock, which was divergently selected for the ability of ewes to rear multiple offspring. Phenotypic and genetic trends in FWEC of the divergently selected lines were inspected for possible divergence that was indicative of correlated responses to the divergent selection regime. Simultaneously, the reciprocal cross between the two lines was assessed for possible heterotic effects in FWEC.

\section{Materials and Methods}

Data were obtained from Elsenburg Merino flock, which were divergently selected for their ability to rear multiple offspring. Details of the selection procedure for the resource flock and experimental site have been documented in the literature (Cloete \& Scholtz, 1998; Cloete et al., 2004; 2009; Scholtz et al., 2010). Briefly, two lines of sheep that differ in reproductive performance were developed from 1986. One line was selected for increased reproductive performance ( $\mathrm{H}$-line), based on its ability to rear more than one lamb per lambing opportunity. The other line (L-line) was selected based on zero lamb output at one or more lambing opportunities, that is, ewes were barren or lost all lambs born at least once. Initial selection of rams and ewes were based on maternal ranking values for number of lambs weaned (see Cloete et al., 2004). Selection was thus based on performance in the previous generation. From 2002, following on from results reported by Cloete et al. (2004), predicted breeding values from single-trait repeatability models were used to aid selection decisions. In the early stages of the selection experiment, ewes that reared a single lamb per lambing opportunity were occasionally accepted in both lines, depending on reproduction rates and replacement needs. As expected, few offspring have been available in the L-line in recent years owing to downward selection, so the progeny from ewes that rear at least a single lamb per mating often had to be selected to maintain the line. Selection decisions were preferably based on three or more maternal joinings, especially for rams.

Divergent selection for reproductive traits resulted in lines that differ in the reproduction traits selected for, namely number of lambs weaned and weight of lamb weaned per ewe mated (Cloete et al., 2004), lamb survival (Cloete et al., 2009), susceptibility to breech strike (Scholtz et al., 2010), behaviour (Cloete et al., 2005; 2010) and adrenal function (Van der Walt et al., 2009; Hough et al., 2015). In all these studies, the $\mathrm{H}$-line showed superior ability to reproduce and survive, resist breech strike, and adapt to stressful situations, compared with the L-line. Both lines were maintained at Elsenburg Research Farm as a single flock, except during joining in single-sire groups to 2 - 7 rams. The experimental farm is situated approximately $10 \mathrm{~km}$ north of Stellenbosch at $33^{\circ} 51^{\prime} \mathrm{S}$ and $18^{\circ} 50^{\prime} \mathrm{E}$. The climatic conditions at the site are Mediterranean, with $77 \%$ of the total rainfall of $606 \mathrm{~mm}$ being recorded between April and September. The animals were maintained, managed and recorded under clearance from the Departmental Ethical Committee for Research on Animals (DECRA reference numbers R12/57 and S12/58) at Western Cape Department of Agriculture.

There was no direct selection for low FWEC in either of the lines. The descriptions of management of experimental animals and the pastures they utilized were documented by Cloete et al. (2004; 2009), and the faecal grab sampling procedures were detailed by Cloete et al. (2007). Rectal faecal grab samples were collected from individual animals born in 1995 - 1996, 1999 and 2001 - 2013, aged between 9 and 11 months. Two datasets were considered: 1869 FWEC records of animals born in the divergently selected lambs during the birth years provided above; and 851 records of the divergently selected lines and the reciprocal cross between them born from 2003 to 2008. Sampling was conducted after drenching had been withheld for at least 6 - 10 weeks, generally in April, except for 2013, when the individual sample grabs were collected in February. At that time, the animals were likely to be infected with a mixture of helminthic nematodes with the genera Teladorsargia (Ostertagia) and Trychostrongylus spp. present as major species 
and Haemonchus contortus as a minor species (Reinecke et al., 1987). Individual faecal samples were analysed at Stellenbosch Provincial Veterinary Laboratory, using the McMaster technique, with a sensitivity of 100 eggs per gram (epg) of wet faeces (Van Schalkwyk et al., 1994; Matebesi-Ranthimo et al., 2014).

Faecal worm egg count is known to be exceedingly variable and skewed, needing transformation prior to analysis (Greeff et al., 1995; Khusro et al., 2004; Morris et al., 2005; Cloete et al., 2007). Commonly used transformations that are applied to FWEC data are the cube root transformation and the log transformation. Both have been used in the past to normalize FWEC data (Morris et al., 2005; Cloete et al., 2007; MatebesiRanthimo et al., 2014). Log transformation involves the calculation of the natural logarithm of FWEC, after 100 is added to FWEC to account for zero counts. ASREML software (Gilmour et al., 2009) was used to analyse the fixed effects and to estimate variance components in single-trait analyses. The first analysis involved fitting various combinations of fixed effects to obtain an operational model, including the effects of selection line ( $H$ or $L)$, birth year (as specified above), sex (ram and ewe), age of dam (2 - 7+ years) and birth type (singles and pooled multiples). All two-factor interactions were considered initially, but only the birth year $x$ sex interaction was significant and retained in the operational model, along with the selection line $x$ birth year interaction. The latter interaction would be indicative of phenotypic divergence, possibly associated with correlated responses to the selection regime. Random terms were added sequentially to the operational model, yielding these models for analyses (in matrix notation):

$$
\begin{aligned}
& y=X b+e \\
& y=X b+Z_{1} a+e \\
& y=X b+Z_{1} a+Z_{2} c+e \\
& y=X b+Z_{1} a+Z_{3} m+e \\
& {[\text { Covariance }(\mathrm{a}, \mathrm{m})=0]} \\
& y=X b+Z_{1} a+Z_{3} m+e \\
& {\left[\text { Covariance }(\mathrm{a}, \mathrm{m})=A \sigma_{\mathrm{am}}\right]} \\
& y=X b+Z_{1} a+Z_{3} m+Z_{2} c+e \\
& {[\text { Covariance }(\mathrm{a}, \mathrm{m})=0]} \\
& y=X b+Z_{1} a+Z_{3} m+Z_{2} c+e \\
& {\left[\text { Covariance }(\mathrm{a}, \mathrm{m})=\mathrm{A} \sigma_{a m}\right]}
\end{aligned}
$$

In these analyses, y was a vector of observations for untransformed FWEC, cube-root-transformed FWEC and log-transformed FWEC, and $b, a, m$ and $c$ were vectors of fixed effects, direct genetic variances, maternal genetic variances, and maternal permanent environmental variances, respectively. $X, Z_{1}, Z_{2}$ and $Z_{3}$ represented the corresponding incidence matrices relating the effects to $y$, and $e$ was the randomly distributed vector of residuals. A was the numerator relationship matrix, and $\sigma_{\mathrm{am}}$ the covariance between direct and maternal additive genetic effects.

It was assumed that:

$$
V(a)=A \sigma_{a}^{2} ; \mathrm{V}(\mathrm{m})=\mathrm{A} \sigma_{\mathrm{m}}^{2} ; \mathrm{V}(\mathrm{c})=\mathrm{I} \sigma_{\mathrm{c}}^{2} ; \mathrm{V}(\mathrm{e})=\mathrm{I} \sigma_{\mathrm{e}}^{2}
$$

with I representing identity matrices; $b_{a}^{2}, \quad b_{m}^{2}, \quad b_{c}^{2}$, and $b_{e}^{2}$ being the direct genetic, maternal genetic, maternal permanent environmental (PE) and residual variances, respectively. Ratios corresponding to additive genetic and permanent environmental variances were computed from these estimates. These variances were expressed relative to the total phenotypic variance. Likelihood ratio tests (LRTs) were used to test the contribution of each random term to improvements in the operational model for significance. An LRT is based on testing twice the increase in the log likelihood resulting from adding an additional random term to the model as a chi-squared statistic. For two models with the same number of random terms, the model with the higher value for the LRT fitted the data better, if identical fixed effects were modelled.

Animal solutions, reflecting additive estimated breeding values (EBVs) for log-transformed FWEC were obtained for individuals. These breeding values were added to the overall log-transformed mean and transformed back to the observed scale. The overall geometric mean was again subtracted from the 
individual values and averaged for the selection lines in birth years. Genetic trends derived in this way were inspected for differences between lines, using standard errors of means to inspect line differences in birth years for significance. EBVs were obtained from an analysis in which the selection line and its interactions with other fixed effects were excluded from the operational model.

Additionally, the data of 851 progeny were extracted from the raw data file to represent the purebred $\mathrm{H}$ and $L$ lines, as well as the reciprocal cross between them for the $2003-2008$ birth years. The same fixed effects were fitted to this data, but the two crossbred genotypes were added to the two purebred lines considered initially. A linear contrast was defined in ASREML to compare the reciprocal crossbred progeny with the mid-parent value of the two purebred lines. All genetic analyses included the full pedigree file for the dataset, consisting of 5596 individuals, the progeny of 242 sires and 1552 dams.

\section{Results}

The standard deviation of raw FWEC records across lines exceeded the mean value, recorded values ranging from 0 to $27600 \mathrm{epg}$ of wet faeces (Table 1). The distribution of FWEC data was improved appreciably by the appropriate transformation, resulting in a coefficient of variance of $21 \%$ for log-transformed FWEC.

Least squares means of fixed effects for log-transformed FWEC are presented in Table 2. Conclusions derived from analyses of untransformed FWEC and cube-root-transformed FWEC were in close correspondence with the results presented and were therefore omitted. Log-transformed FWEC was affected markedly by birth year $(P<0.001)$, means ranging from 111 epg of wet faeces in 2013 to $3646 \mathrm{epg}$ in 2011. The overall log-transformed FWEC of ram lambs was almost double that of ewe lambs $(P<0.001)$. In contrast, log-transformed FWEC was not affected by dam age, selection line and sex $(P>0.20)$.

Table 1 Descriptive statistics for faecal worm egg counts (FWEC) of 1869 Merino progeny before and after transformation

\begin{tabular}{lccrc}
\hline Trait analysed & Mean & SD & CV (\%) & Range \\
\hline Raw FWEC & 1774 & 2767 & 148 & $0-27600$ \\
Cube root of FWEC & 9.02 & 6.07 & 67 & $0-30.2$ \\
Log of FWEC & 6.65 & 1.41 & 21 & $4.61-10.2$ \\
\hline
\end{tabular}

Log-transformed FWEC was affected by the interaction between birth year and sex (Figure 1). Generally, the least squares means for rams were above those of ewes, in many cases significantly so. However, this pattern was interrupted in 2010, when ewes had markedly higher log-transformed FWEC means than rams. No significant sex differences could be discerned in some other years, contributing to the observed sex $x$ birth year interaction.

In contrast, there was no evidence of interaction between selection line and birth year in phenotypic means (Figure 2). The lines for the $\mathrm{H}$ and $\mathrm{L}$ lines followed each other closely, and even though absolute differences could occasionally be discerned between lines, none of these was significant $(P>0.05)$.

Log-likelihood values for the analyses of FWEC suggest a significant improvement from the model with fixed effects only to the model that included direct additive genetic variation for untransformed FWEC, as well as for cube-root-transformed and log-transformed FWEC $(P<0.05$; Table 3$)$. However, the addition of further random effects failed to result in improvement to the goodness of fit of the model employed.

All heritability estimates for FWEC reached a level of at least double the corresponding standard error and therefore differed from zero $(P<0.05$; Table 4). Although transformation resulted in higher heritability estimates in absolute terms, even transformed FWEC remained lowly heritable at $0.09-0.10$. 
Table 2 Least square means $( \pm$ SE) and estimated back transformed values ( \pm approximate SE derived from ASREML) for log-transformed faecal worm egg counts (FWEC) as affected by birth year, sex, selection line, age of dam and birth type

\begin{tabular}{|c|c|c|c|}
\hline Fixed effect and level & Number of observations & Log-transformed FWEC & Geometric mean \\
\hline Birth year & & $\star \star *$ & \\
\hline 1995 & 148 & $5.64 \pm 0.11$ & $181 \pm 32$ \\
\hline 1996 & 169 & $6.58 \pm 0.11$ & $620 \pm 76$ \\
\hline 1999 & 121 & $5.58 \pm 0.12$ & $166 \pm 31$ \\
\hline 2002 & 94 & $7.52 \pm 0.16$ & $1737 \pm 297$ \\
\hline 2003 & 115 & $6.63 \pm 0.13$ & $655 \pm 101$ \\
\hline 2004 & 77 & $7.38 \pm 0.25$ & $1498 \pm 409$ \\
\hline 2005 & 105 & $7.91 \pm 0.16$ & $2612 \pm 428$ \\
\hline 2006 & 147 & $7.07 \pm 0.14$ & $1072 \pm 168$ \\
\hline 2007 & 125 & $7.41 \pm 0.20$ & $1555 \pm 336$ \\
\hline 2008 & 127 & $6.70 \pm 0.17$ & $714 \pm 140$ \\
\hline 2009 & 100 & $6.45 \pm 0.23$ & $530 \pm 147$ \\
\hline 2010 & 114 & $6.28 \pm 0.18$ & $433 \pm 94$ \\
\hline 2011 & 140 & $8.23 \pm 0.15$ & $3646 \pm 553$ \\
\hline 2012 & 145 & $6.43 \pm 0.14$ & $522 \pm 84$ \\
\hline 2013 & 142 & $5.35 \pm 0.13$ & $111 \pm 28$ \\
\hline Sex & & $\star \star \star *$ & \\
\hline Ram & 888 & $7.01 \pm 0.08$ & $1006 \pm 88$ \\
\hline Ewe & 981 & $6.48 \pm 0.08$ & $550 \pm 52$ \\
\hline Selection line & & 0.40 & \\
\hline H Line & 1569 & $6.79 \pm 0.08$ & $787 \pm 74$ \\
\hline L line & 300 & $6.70 \pm 0.13$ & $711 \pm 102$ \\
\hline Age of dam (year) & & 0.64 & \\
\hline 2 & 399 & $6.79 \pm 0.09$ & $785 \pm 80$ \\
\hline 3 & 627 & $6.69 \pm 0.08$ & $705 \pm 68$ \\
\hline 4 & 311 & $6.78 \pm 0.08$ & $777 \pm 80$ \\
\hline 5 & 248 & $6.78 \pm 0.09$ & $780 \pm 83$ \\
\hline 6 & 162 & $6.73 \pm 0.10$ & $738 \pm 87$ \\
\hline $7+$ & 122 & $6.69 \pm 0.11$ & $708 \pm 89$ \\
\hline Birth type & & 0.39 & \\
\hline Single & 871 & $6.76 \pm 0.08$ & $766 \pm 68$ \\
\hline Multiple & 998 & $6.72 \pm 0.08$ & $731 \pm 67$ \\
\hline
\end{tabular}

*** $P<0.001$, actual significant levels for $P>0.05$. 


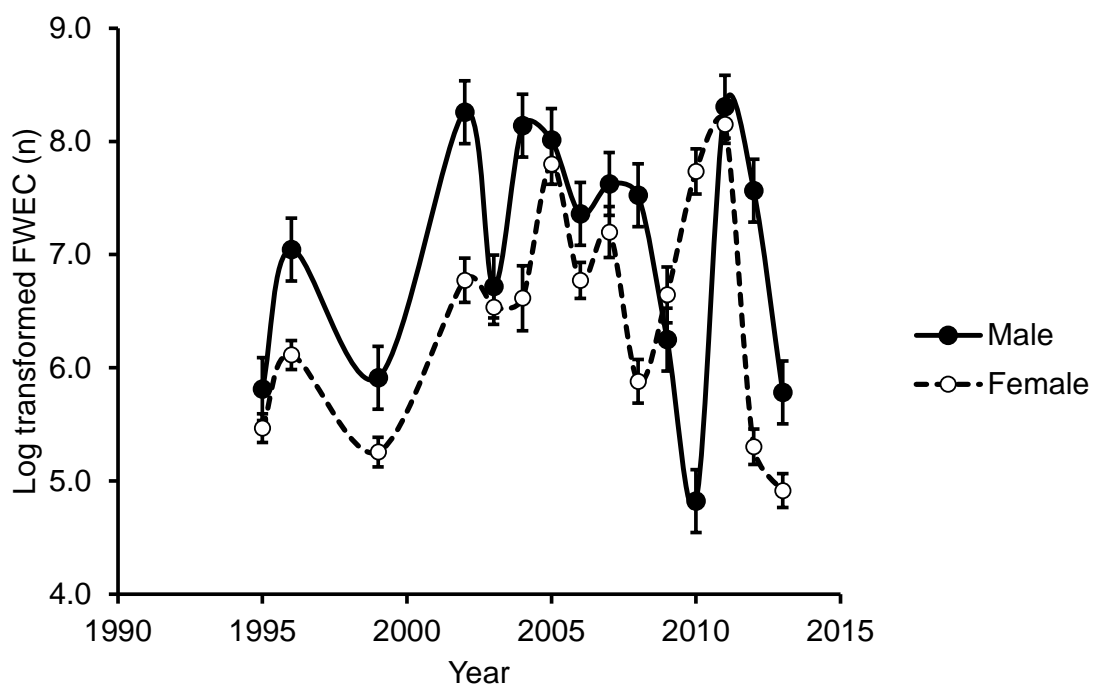

Figure 1 Least square means (SE as vertical bars about the mean) depicting the birth year $\mathrm{x}$ sex interaction for log-transformed faecal worm egg counts (FWEC).

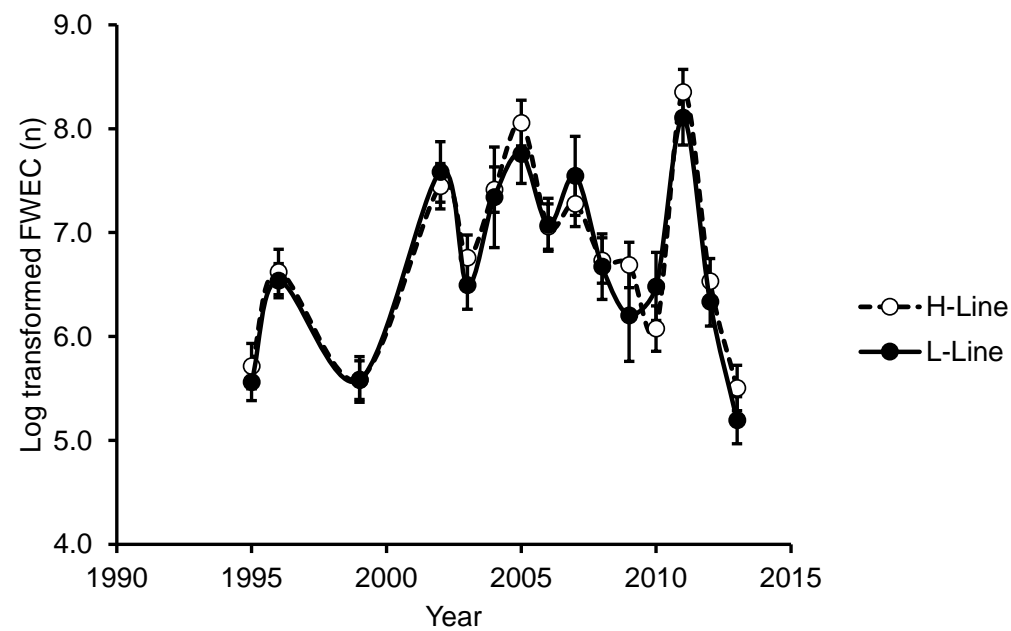

Figure 2 Least square means (SE as vertical bars about the mean) depicting the selection line $\mathrm{x}$ birth year interaction for log-transformed faecal worm egg counts (FWEC).

Table 3 Log-likelihood (LogL) values for models ${ }^{a}$ fitting different random effects for faecal worm egg counts (FWEC) in single-trait animal model analysis. The best model is denoted in bold

\begin{tabular}{lccc}
\hline Model $^{\mathrm{a}}$ & Raw FWEC & $\begin{array}{c}\text { Cube root transformed } \\
\text { FWEC }\end{array}$ & $\begin{array}{c}\text { Log transformed } \\
\text { FWEC }\end{array}$ \\
\hline $\mathrm{FE}$ & -4975.18 & -3566.26 & -884.434 \\
$\mathrm{FE}+b_{a}^{2}$ & -4972.00 & -3563.26 & $\mathbf{- 8 8 1 . 2 8 4}$ \\
$\mathrm{FE}+\mathrm{b}_{a}^{2}+b_{c}^{2}$ & -4971.34 & -3561.80 & -879.981 \\
$\mathrm{FE}+b_{a}^{2}+b_{m}^{2}$ & -4971.40 & -3562.33 & -880.085 \\
$\mathrm{FE}+b_{a}^{2}+b_{m}^{2}+r_{A M}$ & -4971.22 & -3561.72 & -879.733 \\
$\mathrm{FE}+b_{a}^{2}+b_{c}^{2}+b_{m}^{2}$ & -4971.24 & -3562.23 & -880.084 \\
$\mathrm{FE}+b_{a}^{2}+b_{c}^{2}+b_{m}^{2}+r_{A M}$ & -4971.09 & -3561.65 & -879.753
\end{tabular}

${ }^{a}$ FE: fixed effects only; $\quad b_{a}^{2}:$ direct genetic effect; $b_{m}^{2}:$ dam genetic effect; $\quad b_{c}^{2}$ : dam PE effect. 
Table 4 Variance components and ratios $( \pm$ SE) for raw and transformed faecal worm egg counts (FWEC) estimated from single-trait analyses

\begin{tabular}{lccc}
\hline Trait analysed & $\boldsymbol{\sigma}_{\mathbf{a}}{ }^{2}$ & $\boldsymbol{\sigma}_{\mathrm{e}}{ }^{2}$ & $\mathbf{h}^{\mathbf{2}}$ \\
\hline Raw FWEC & 280669 & 4475170 & $0.06 \pm 0.03$ \\
Cube root of FWEC & 1.462 & 15.489 & $0.09 \pm 0.04$ \\
Log of FWEC & 0.084 & 0.804 & $0.10 \pm 0.04$ \\
\hline
\end{tabular}

$\sigma_{a}^{2}$ : direct additive variance; $\sigma_{e}^{2}$ : residual variance; $h^{2}$ : direct, additive heritability.

There was no compelling evidence of genetic change in back-transformed FWEC in either line during the experiment, as most annual means oscillated between -45 and 54 epg wet faeces (Figure 3 ). According to the standard errors, there were only a few years in which significant $(P<0.05)$ differences occurred between the averaged estimated breeding values derived for the purebred lines. It thus seems that the resistance of the experimental animals to gastrointestinal nematodes, as reflected by FWEC, was largely independent of the divergent selection practices for the ability of ewes to rear multiples that were applied in the resource population. Overall mean breeding values ( \pm SE) across years amounted to $-9.2 \pm 1.7$ epg wet faeces in the $\mathrm{H}$ line and $-11.2 \pm 3.6 \mathrm{epg}$ wet faeces in the $\mathrm{L}$ line.

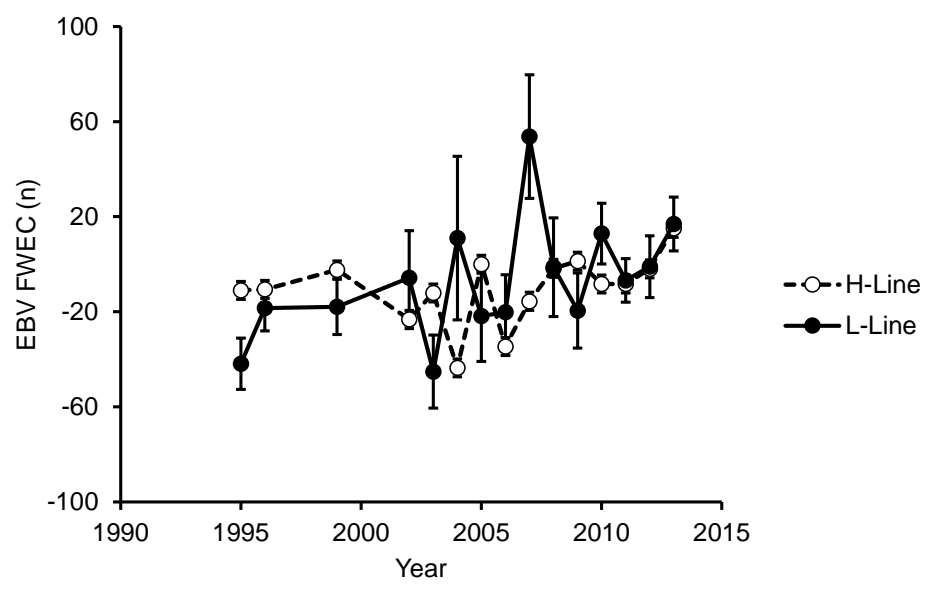

Figure 3 Annual means (SE as vertical bars about the mean) of back-transformed estimated breeding values (EBV) for faecal worm egg counts to indicate genetic change that took place during the duration of the experiment.

Table 5 Least squares means ( \pm SE) for log-transformed faecal worm egg counts (FWEC) of the divergently selected $H$ and $L$ lines and the reciprocal cross among them for the period $2003-2008$

\begin{tabular}{lcccc}
\hline Sire line & Dam line & Number of observations & Log transformed FWEC & Geometric mean \\
\hline \multirow{2}{*}{ H line } & H Line & 622 & $7.13 \pm 0.04$ & $1152 \pm 52$ \\
& L Line & 55 & $7.22 \pm 0.19$ & $1262 \pm 264$ \\
\multirow{2}{*}{ line } & H Line & 100 & $7.24 \pm 0.10$ & $1301 \pm 140$ \\
& L Line & 74 & $7.21 \pm 0.12$ & $1248 \pm 168$ \\
\hline
\end{tabular}

Log-transformed FWEC was independent of genotype in the reciprocal crossbreeding study conducted from 2003 to 2008 (Table 5). Means for the purebred lines were similar $(P>0.05)$, as in Table 2. The reciprocal crossbred progeny did not differ from either purebred line or the mid-parent value $(P>0.05)$. 


\section{Discussion}

In this paper, environmental and genetic factors that affected FWEC, an indirect measure of parasite resistance in Merino lines divergently selected for reproductive performance, were explored. A dataset of 2720 records enabled unique statistical analyses to be run. There was a relatively high individual variation of FWEC across the lines, ranging from 0 to 27600. Extreme individual variation of FWEC is commonly reported in literature. Studies by Cloete et al. (2007), Snyman (2007) and Matebesi-Ranthimo et al. (2014) reported an individual variation for FWEC ranging from 0 to 13700,0 to 87800 and 0 to 32700 epg wet faeces, respectively. In a study by Khusro et al. (2004), means for FWEC were 736 for hoggets and 779 for yearling Merino sheep, while the individual variation for FWEC ranged from 0 to 50000 epg in both age groups. The transformations used in this study are commonly applied to improve the extreme variation in data of this nature. Safari \& Fogarty (2003) documented genetic parameters of sheep, among others, for FWEC. In their study, 26 heritability estimates for FWEC were reported, in 12 of which a cube transformation was applied and a log transformation in the other 14. Means in these studies ranged from 2.75 to 22.6 for cube-transformed data and from 6.88 to 7.49 for log-transformed data. In studies by Cloete et al. (2007) and Matebesi-Ranthimo et al. (2014) the coefficient of variation in FWEC records exceeded $100 \%$ before transformation and reduced to below $20 \%$ after log transformation. Similar results were found in this study, but the magnitude of CV was slightly higher, that is, up to $21 \%$ after transformation. Higher CV values are indicative of appreciable phenotypic variation, which could enable genetic gains, even at modest levels of heritability. The results provided in this study are consistent with those reported in the literature.

Pertaining to the interaction between birth year and sex, the results obtained in this study are in accordance with those obtained by Khusro et al. (2004), Cloete et al. (2007) and Matebesi-Ranthimo et al. (2014). In all three studies, the effects of birth year and sex were involved in a significant interaction. In a study by Khusro et al. (2004), the direction of the magnitude of difference in FWEC varied between yearling animals and hoggets. In yearling animals, ewes excreted more eggs than rams, while the opposite was true of hoggets. Cloete et al. (2007) and Matebesi-Ranthimo et al. (2014), on the other hand, observed fewer eggs in ewes than in rams, but the magnitude was different between years, resulting in a significant interaction. A significant interaction effect of birth year by sex observed in this study could be random or could be a sign that there is no uniform environment. Males and females were kept in different paddocks and therefore were grazed separately. So, it is possible that males were generally grazed on paddocks with a higher parasite load compared with females. One of the problems of doing an experiment based on natural challenge is that the researcher does not have much control over the level of infestation that the experimental units receive, while some environments do not support an adequate helminth population. Therefore some studies resort to dosing the experimental units with a fixed number of infective worm larvae to ensure an adequate challenge throughout. However, artificially dosing animals with a defined number of nematode larvae is labour intensive and costly, it could be debated on ethical grounds, and it could be problematic to source infective larvae sustainably. Gauly et al. (2006) evaluated the effect of sex on resistance of sheep lambs to an experimental Haemonchus contortus infection. In their study, male lambs excreted more FWEC compared with females, suggesting that females were more resistant than males. While the sex $x$ year interaction is clearly related to grazing separate pastures, there seems to be some support for the contention that ewes are generally better able to resist nematode infestation than rams.

The heritability estimates reported in this study were fairly low at 0.10 after transformation, suggesting a fairly small genetic component for FWEC and that selection based on FWEC is likely to be slow. The present heritability estimates are on the lower end of the range of literature values. Published heritability estimates for FWEC in Merino flocks under natural challenge in South African conditions were moderate, ranging from 0.14 to 0.24 (Niewoudt et al., 2002; Cloete et al., 2007; Matebesi-Ranthimo et al., 2014). In a study by Niewoudt et al. (2002), the log-transformed FWEC data yielded the heritability estimate of 0.24. Cloete et al. (2007) reported heritability estimates of 0.14 to 0.18 (depending on transformation of the data) in 13 to 16-months old Merino sheep sampled in the spring. Similar results were found by MatebesiRanthimo et al. (2014) in the same flock and utilizing a larger dataset. The heritability estimates reported in South African literature, however, are lower than the mean value of 0.27 derived from a mixture of artificial and natural challenges (reviewed by Safari et al., 2005). Heritability estimates for FWEC in Merino sheep have been reported in Australia. The results showed a range of 0.18 to 0.40 for weaners, 0.17 to 0.34 after weaning and 0.15 to 0.40 in one-year-old sheep, with standard errors ranging from 0.04 to 0.12 (Clarke, 2002). Moreover, in New Zealand, the heritability estimates for FWEC was 0.37 in naturally challenged Romney sheep in a temperate environment (Baker et al., 1991). As a result, selection for parasite resistance resulted in realized gains (Woolaston \& Piper, 1996; Karlsson \& Greeff, 2006).

Scientific literature reports that FWEC can be influenced by seasonal variation, management practice and geographical area (Greeff et al., 1995). Gregory et al. (1940) found seasonal variation as one of the factors affecting parasite resistance. Greeff et al. (1995) estimated the genetic constitution of FWEC at 
various times of the year in Merino lambs born in a Mediterranean environment. In their study, the heritability estimates for FWEC under natural challenge was high from June to October (i.e. 0.21 to 0.25 ), and low from February to April (0.00 to 0.03 ), while a peak of 0.51 was reached in July. In the same study, Greeff et al. (1995) found a large variation of FWEC between months within years, and across years, suggesting that the effect of season should not be neglected when planning genetic evaluation studies of parasite resistance. The environment to which sheep are subjected is often characterized by seasonal rainfall events and temperature fluctuations. As a result, the quality and quantity of pasture and the development of infective larvae vary. Studies by Niewoudt et al. (2002), Cloete et al. (2007) and Matebesi-Ranthimo et al. (2014) collected faecal samples between July and September. The moderate heritability estimates obtained coincided with the growth of green lush pasture and hatching of eggs after first rains. In this study, the faecal samples were collected in late summer and autumn. The low heritability estimates could be attributed to seasonal variation and grab sampling when the expected heritability of FWEC is low (Greeff et al., 1995), despite adequate challenge. In addition, the lower heritability estimates for FWEC in the current study could result from a relatively low accuracy of $100 \mathrm{epg}$ of wet faeces compared with some other studies. In a study by Notter (2003), the heritability estimates for FWEC were $0.42,0.22$ and 0.25 at 3,4 and 5 weeks post infection with $\mathrm{H}$. contortus in sheep. In the latter study, faecal worm egg counts were calculated at a sensitivity of $50 \mathrm{epg}$.

Realized genetic responses in relation to the phenotypic means in the $\mathrm{H}$ line amounted to $1.3 \%$ for number of lambs born and $1.5 \%$ for number of lambs weaned (Cloete et al., 2004). Corresponding downward trends in the L-line amounted to $0.6 \%$ and $1.0 \%$, respectively. Responses in reproduction were clearly divergent in the selection lines in contrast with those for FWEC in Figure 3, suggesting no statistical evidence of genetic change in both lines. Based on these results, a negligible genetic relationship between reproduction and FWEC could be assumed. Studies by Morris et al. (2010) and Pickering et al. (2012) agree with these findings in that they reported no evidence of sizable genetic correlations between FWEC and reproduction. Pickering et al. (2012) reported that FWEC1 (faecal worm egg count in summer) and FWEC2 (faecal worm egg count in autumn) were not highly correlated with the number of lambs born per ewe $(0.03 \pm$ 0.03 and $0.04 \pm 0.03$, respectively). Morris et al. (2010) reported a non-significant genetic correlation between FWEC and litter size. However, a small correlated genetic response to FWEC selection was observed in another study by Morris et al. (2000), with litter size being greater (i.e. 0.11 more lambs weaned/ewe) in the parasite-resistant line than the control line. In contrast, the present study failed to provide evidence of a correlated response in FWEC to selection for reproduction, and seem to be consistent with the reported genetic correlations.

\section{Conclusion and future direction}

The present study indicated that while FWEC had a low heritability in the resource population, selection would be aided by adequate levels of phenotypic variation. The lack of phenotypic or genetic change in the divergently selected lines suggests that the genetic correlation of number of lambs weaned per ewe mated with FWEC was likely to be negligible. This finding was supported by genetic correlations cited from the literature, albeit on a different reproduction trait, namely number of lambs born. Since the experimental animals in this study were challenged only in autumn, the results may not be applicable to a different season. Future work is needed to determine the effect of season on the genetic components of internal parasite resistance in South African conditions.

\section{Acknowledgements}

The contribution of D. Marang, Z. Stentyi and S. Stentyi to the maintenance and recording of the resource flock is acknowledged with gratitude. The research reported in this paper was funded jointly by the South African Wool Industry, Western Cape Agricultural Research Trust and THRIP initiative of the National Research Foundation.

\section{References}

Baker, R.L., Watson, T.G., Bisset, S.A., Vlassoff, A. \& Douch, P.G.C., 1991. Breeding sheep in New Zealand for resistance to internal parasites: Research results and commercial application. In: Breeding for Disease Resistance in Sheep. Eds: Gray, G.D. \& Woolaston, R.R., Australian Wool Corporation, Melbourne. pp. 19-32.

Barger, I.A. \& Cox, H.W., 1984. Wool production of sheep chronically infected with Haemonchus contortus. Vet. Parasitol. 15,169-175.

Chiezey, N.P., Ajanusi, O.J. \& Oyedipe, E.O., 2008. The reproductive performance of sheep carrying natural infections of gastro-intestinal nematodes. Asian J. Anim. Vet. Adv. 3, 236-243. 
Clarke, B., 2002. Review of genetic parameters for Australian Merino sheep. Report to Meat and Livestock Australia; project no. SHGEN. 005. Department of Agriculture of Western Australia, Perth.

Cloete, S.W.P. \& Scholtz, A.J., 1998. Lamb survival in relation to lambing and neonatal behaviour in medium wool Merino lines divergently selected for multiple rearing ability. Aust. J. Exp. Agric. 38, 801-811.

Cloete, S.W.P., Gilmour, A.R., Olivier, J.J. \& Van Wyk, J.B., 2004. Genetic and phenotypic trends and parameters in reproduction, greasy fleece weight and live weight in Merino lines divergently selected for multiple rearing ability. Aust. J. Exp. Agric. 44, 745-754.

Cloete, J.J.E., Hoffman, L.C. \& Cloete, S.W.P., 2005. Behaviour of Merinos divergently selected for multiple rearing ability in response to external stimuli. Small Rumin. Res. 60, 227-236.

Cloete, S.W.P., Olivier, J.J., Du Toit, E. \& Dreyer, F.H., 2007. Genetic analysis of faecal worm egg count in South African Merinos under natural challenge. S. Afr. J. Anim. Sci. 37, 237-247.

Cloete, S.W.P., Misztal, I. \& Olivier, J.J., 2009. Genetic parameters and trends for lamb survival and birth weight in a Merino flock divergently selected for multiple rearing ability. J. Anim. Sci. 87, 2196-2208.

Cloete, J.J.E., Cloete, S.W.P. \& Hoffman, L.C., 2010. Behaviour of Merinos selected for multiple rearing ability in response to human beings. Proc. 9th World Cong. Gen. Appl. Livest. Prod.1-6.

Dash, K.M., 1986. Control of helminthosis in lambs by strategic treatment with closantel and broad-spectrum anthelmintics. Aust. Vet. J. 63, 47-48.

Gauly, M., Schackert, M., Hoffmann, B. \& Erhardt, G., 2006. Influence of sex on the resistance of sheep lambs to an experimental Haemonchus contortus infection. Dtsch Tierarztl Wochenschr. 113, 178-181.

Gilmour, A.R., Gogel, B.J., Cullis, B.R. \& Thompson, R., 2009. ASReml User Guide, Release 3.0. VSN International Ltd, Hemel Hempstead, HP1 1ES, UK. www.vsni.co.uk.

Gray, G.D., 1991. Breeding for resistance to trichostrongyle nematodes in sheep. In: Breeding for Disease Resistance in Farm Animals. Eds: Owen, J.B. \& Oxford, R.F.E., CAB Int. Wallingford. pp. 187-200.

Greeff, J.C., Karlsson, L.J.E. \& Harris, J.F., 1995. Heritability of faecal worm egg count at different times of the year in a Mediterranean environment. Proc. Aust. Assoc. Anim. Breed. Gen. 11, 117-121.

Gregory, P.W., Miller, R.F. \& Stewart, M.A., 1940. An analysis of environmental and genetic factors influencing stomach worm infestation in sheep. J. Gen. 39, 391-400.

Hough, D., Storbeck, K., Cloete, S.W.P., Swart, A.C. \& Swart, P., 2015. Relative contribution of P450c17 towards the acute cortisol response: Lessons from sheep and goats. Molec. Cell. Endocrinol. 408, 107-113.

Karlsson, L.J.E. \& Greeff, J.C., 2006. Selection response in faecal worm egg counts in the Rylington Merino parasite resistant flock. Aust. J. Exp. Agric. 46, 809-811.

Kelly, G.A., Kahn, L.P. \& Walkden-Brown, S.W., 2010. Integrated parasite management for sheep reduces the effects of gastrointestinal nematodes on the Northern Tablelands of New South Wales. Anim. Prod. Sci. 50, 1043-1052.

Kenyon, F., Greer, A.W., Coles, G.C., Cringoli, G., Papadopoulos, E., Cabaret, J., Berrag, B., Varady, M., Van Wyk, J.A., Thomas, E., Vercruysse, J. \& Jackson, F., 2009. The role of targeted selective treatments in the development of refugia-based approaches to the control of gastrointestinal nematodes of small ruminants. Vet. Parasitol. 164, 3-11.

Khusro, M., Van der Werf, J.H.J., Brown, D.J. \& Ball, A., 2004. Across flock (co)variance components for faecal worm egg count, live weight, and fleece traits for Australian Merinos. Livest. Prod. Sci. 91, 35-43.

Mandonnet, N., Aumont, G., Fleury, R., Varo, H., Gruner, L., Bouix, J. \& Vu Tien Khangs, J., 2001. Assessment of genetic variability of resistance to gastrointestinal nematode parasites in Creole goats in humid tropics. J. Anim. Sci. 79, 1706-1702.

Matebesi-Ranthimo, P.A.M., Cloete, S.W.P., Van Wyk, J.B. \& Olivier, J.J., 2014. Genetic parameters and relationships of faecal worm egg count with objectively measured wool traits in the Tygerhoek Merino flock. S. Afr. J. Anim. Sci. 44, 178-188.

McLeod, R.S., 1995. Costs of major parasites to the Australian livestock industries. Int. J. Parasitol. 25, 1363-1367.

Molento, M.B., Fortes, F.S., Pondelek, D.A.S., Borges, F.A., Chagas, A.C.S., Torres-Acosta, J.F.J. \& Geldhof, P., 2011. Challenges of nematode control in ruminants: Focus on Latin America. Vet. Parasitol. 180, 126-132.

Morris, C.A., 2011. Review of genetic parameters for disease resistance in sheep in New Zealand and Australia. Proc. Assoc. Advmt. Anim. Breed. Genet. 18, 263-271.

Morris, C.A., Vlassoff, A., Bisset, S.A., Baker, R.L., Watson, T.G., West, C.J. \& Wheeler, M., 2000. Continued selection of Romney sheep for resistance or susceptibility to nematode infection: estimates of direct and correlated responses. Anim. Sci. 70, 17-27. 
Morris, C.A., Wheeler, M., Watson, T.G., Hosking, B.C. \& Leathwick, D.M., 2005. Direct and correlated responses to selection for high or low faecal nematode egg count in Perendale sheep. N. Z. J. Agric. Res. 48, 1-10.

Morris, C.A., Wheeler, M. \& Shaw, R.J., 2010. Correlated responses following genetic selection to change faecal egg count in Romney. N. Z. Soc. Sci. 70, 229-234.

Nieuwoudt, S.W., Theron, H.E. \& Krüger, L.P., 2002. Genetic parameters for resistance to Haemonchus contortus in Merino sheep in South Africa. J. S. Afr. Vet. Med. Assoc. 73, 4-7.

Notter, D.R., 2003. Genetics of resistance to Haemonchus contortus infections in sheep. M.Sc. thesis. Blacksburg, Virginia, USA.

Pathak, A.K. \& Tiwari, S.P., 2013. Effect of high plane of nutrition on the performance of Haemonchus contortus infected kids. Vet. World 6, 22-26.

Pickering, N.K., Dodds, K.G., Blair, H.T., Hickson, R.E., Johnson, P.L. \& McEwan, J.C., 2012. Genetic parameters for production traits in New Zealand dual-purpose sheep, with an emphasis on dagginess. J. Anim. Sci. 90, 1411-1420.

Reinecke, R.K., Kirkpatrick, R., Swart, L., Kriel, A.M.D. \& Franck, F., 1987. Parasites in sheep grazing on kikuyu (Penisetum clandestinum) pastures in the winter rainfall region. Onderstepoort J. Vet. Res. 54, 27-38.

Safari, A. \& Fogarty, N.M., 2003. Genetic parameters for sheep production traits: Estimates from the literature. Tech. Bull. No 49, NSW Agriculture, Orange NSW, Australia.

Safari, E., Fogarty, N.M. \& Gilmour, A.R., 2005. A review of genetic parameter estimates for wool, growth, meat and reproduction traits in sheep. Livest. Prod. Sci. 92, 271-289.

Scholtz, A.J., Cloete, S.W.P., Van Wyk, J.B., Kruger, A.C.M. \& Van der Linde, T.C.deK., 2010. Influence of divergent selection for reproduction on the occurrence of breech strike in mature Merino ewes. Anim. Prod. Sci. 50, 203-209.

Snyman, M.A., 2007. Prospects for the utilization of variation in parasite resistance among individual sheep within a flock. Grootfontein Agric. 7, 29-34.

Van der Walt, D., Cloete, S.W.P., Storbeck, K. \& Swart, P., 2009. The role of cytochrome P450 17ahydroxylase/17,20-lyase (CYP17) in the stress coping ability in a divergently selected Merino sheep population. Proc. Assoc. Adv. Anim. Breed. Genet. 18, 100-103.

Van Houtert, M.F. \& Sykes, A.R., 2010. Implications of nutrition for the ability of ruminants to withstand gastrointestinal nematode infections. Int. J. Parasitol. 26, 1151-1167.

Van Schalkwyk, L.W., Schroeder, P.C., Malan, F.S. \& Van Wyk, J.A., 1994. McMaster method of faecal worm egg count. In: Worm workshop: Recommendations on worm control. pp. 19-21.

Woolaston, R.R. \& Piper, L.R., 1996. Selection of Merino sheep for resistance to Haemonchus contortus: Genetic variation. Anim. Sci. 62, 451-460. 